\title{
Antimicrobial Activity of Korean Propolis Extracts on Oral Pathogenic Microorganisms
}

\author{
Jiyeon Roh and Ki-Rim Kim ${ }^{1, \dagger}$ \\ Department of Dental Hygiene, Yonsei University Wonju College of Medicine, Wonju 26426, \\ ${ }^{1}$ Department of Dental Hygiene, Kyungpook National University, Sangju 37224, Korea
}

Propolis has been used as a natural remedy in folk medicine worldwide. The antibacterial, antiviral, antifungal, and antiprotozoal aspects of its antimicrobial properties have been widely investigated. However, few studies focused on its applications in dentistry. Many dental diseases are related to various microorganisms in the oral cavity. In this study, we assessed the antimicrobial activity of Korean propolis extract, collected from 6 different regions, on oral pathogenic microorganisms. The propolis samples, collected from 6 different regions (P1: Uijeongbu, P2: Ansan, P3: Hongcheon, P4: Iksan, P5: Gwangju, and P6: Sangju), were dissolved in ethanol at two different concentrations (10 and $50 \mathrm{mg} / \mathrm{ml})$. Three oral bacteria (Streptococcus mutans, Staphylococcus aureus, and Enterococcus faecalis) and one fungus (Candida albicans) were activated in general broth for 24 hours. Microorganisms were diluted and spread onto agar plates, onto which sterilized $6 \mathrm{~mm}$ filter papers with or without each propolis sample were placed. After 24 hours of incubation, clear zones of inhibition were observed. All tests were performed in triplicate. The propolis samples showed significant antibacterial and antifungal activity on oral pathogenic microorganisms; in addition, low-concentration groups showed outstanding antimicrobial efficacy on the 4 different microorganisms. Among the samples, P6 had significantly higher antibacterial activity than that of the others against three different bacteria. In particular, a high concentration of P6 showed a significant antifungal effect. In conclusion, we confirmed that Korean propolis has an inhibitory effect on oral pathogenic bacteria and fungi. Therefore, we suggest the possibility of developing oral medicine and oral care products based on Korean propolis.

Key Words: Antimicrobial activity, Microorganisms, Oral diseases, Propolis

\section{Introduction}

Propolis has been known for its antibacterial properties in folk medicine, and recently it found application in medicine and cosmetics ${ }^{1}$. It is generally composed of resin and balsam (around 50\%), wax (30\%), essential and aromatic oils (10\%), pollen (5\%), and other substances ${ }^{2}$. There is subtle variability in composition, based on several factors such as botanical sources and geographical zones ${ }^{3)}$.

The oral cavity is a suitable habitat for many microorganisms because of the wet environment and abundance of nutrients. Furthermore, in the oral cavity, soft and hard tissues coexist and form a specific environment that provides both aerobic and anaerobic conditions, in which various microorganisms interact. If the overall oral bacteria decrease because of excessive intake of antibiotics, this may lead to opportunistic infections by fungi. Thus, various factors such as diseases, medicines, or irradiation can cause different oral diseases due to changes in oral microbial flora.

Among oral bacteria, Streptococcus mutans, a major dental caries-inducing bacterium, occupies the largest portion $^{4}$. Enterococcus faecalis, on the other hand, plays a pivotal role in establishing a microbial community by connecting various bacteria in the oral cavity ${ }^{5-7)}$. Staphylococcus aureus, a Gram-positive staphylococcus typically found in the respiratory system, on the skin, and in the oral cavity, is also found in the periodontium where it may 
cause periodontal disease ${ }^{8,9)}$. Candida albicans, the most common fungus in the oral cavity and the gastrointestinal tract, causes opportunistic infections by quickly expanding due to host environmental changes induced by various factors $^{10,11)}$.

Regarding health, products based on natural components have recently gained focus ${ }^{12-14)}$. The biological activity and chemical constituents of propolis have been widely studied, and propolis has been applied using various household items. However, few studies have been conducted on Korean propolis, and insufficient studies assessed its antimicrobial effects on microorganisms that inhabit the oral cavity ${ }^{15-17)}$.

In this study, we investigated the antimicrobial potential of Korean propolis extracts on standard microorganism strains that cause major oral diseases.

\section{Materials and Methods}

\section{Microbial samples}

S. mutans (KCTC 5365), S. aureus (KCTC 1916), E. faecalis (KCTC 5290), and C. albicans (KCTC 17712) were purchased from the Biological Resource Center in Korea Research Institute of Bioscience and Biotechnology (KRIBB). Four types of strains were cultured in Brain Heart Infusion (BHI) broth (Difco; BD, Franklin Lakes, NJ, USA) and Bacto Agar (BD) at $37^{\circ} \mathrm{C}$.

\section{Propolis extracts}

Korean propolis samples, which were collected from various regions of Korea (Fig. 1), were provided by Dong-A University. In brief, crude propolis was extracted with ethanol for 24 hours. The suspensions were separated, concentrated in a rotary evaporator, and redissolved in ethanol. We used two different concentrations of each propolis sample (10 and $50 \mathrm{mg} / \mathrm{ml}$ ), and dimethyl sulfoxide (DMSO) was used as the negative control.

\section{Measurement of microbial growth curve}

Each microorganism was serially diluted 10 -fold using BHI broth, and $100 \mu \mathrm{l}$ of all dilutions were seeded into a 96-well microplate. Microbial growth was determined by following changes in optical density $\left(\mathrm{OD}_{600}\right)$ at $1,3,5,7$, and 18 hours, using a spectrophotometer (Epoch Take3; BioTek, Winooski, VT, USA). Before analysis, the plates were tapped carefully. BHI broth without bacteria was used as blank.

\section{Agar diffusion test}

About $15 \mathrm{ml}$ of BHI agar was poured onto sterile $90 \mathrm{~mm}$ Petri dishes (SPL, Pocheon, Korea) and allowed to solidify at room temperature. A $0.1 \mathrm{ml}$ aliquot of each microbial suspension was spread on the agar plates separately. Six-millimeter filter papers were immersed in $0.1 \mathrm{ml}$ of various propolis samples, and were placed onto the surface of the agar plates. The plates were incubated for 24 hours at $37^{\circ} \mathrm{C}$. The inhibition zones around each group were measured with Vernier calipers (Mitutoyo, Kawasaki, Japan).

\section{Statistical analysis}

All experiments were repeated at least 3 times independently. Data are expressed as the mean value \pm standard deviation. One-way analysis of variance (ANOVA) was performed to detect the significant effects of variables, followed by Tukey's test (IBM SPSS Statistics 23.0; IBM Co., Armonk, NY, USA). The differences were considered significant at $\mathrm{p}<0.05$.

\section{Results}

\section{Growth curves of oral microorganisms}

Growth curves of four different oral microorganisms are

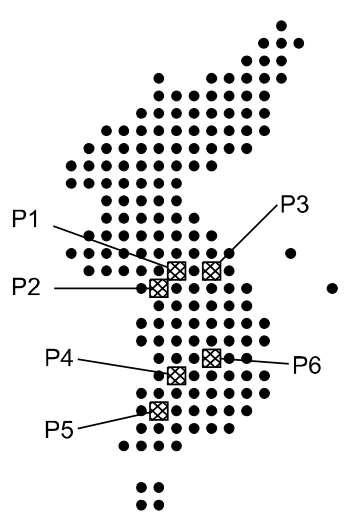

Fig. 1. Collection sites of Korean propolis. P1: Uijeongbu, P2: Ansan, P3: Hongcheon, P4: Iksan, P5: Gwangju, P6: Sangju. 
shown in Fig. 2. All microorganisms were incubated for 20 to 22 hours at $37^{\circ} \mathrm{C}$. According to the curve graph, the last exponential phase of each microorganism was used for this study.

\section{Antimicrobial activity by agar diffusion test}

All propolis samples showed significant antibacterial and antifungal activity in oral pathogenic microorganisms, and there was no zone of inhibition in the negative control. Low concentration groups $(10 \mathrm{mg} / \mathrm{ml})$ showed antimicrobial effects in all tested microorganisms (Table 1, Fig. 3). Propolis from P1 and P6 significantly suppressed $S$. mutans at both concentrations $(\mathrm{p}<0.05)$. The sample P6

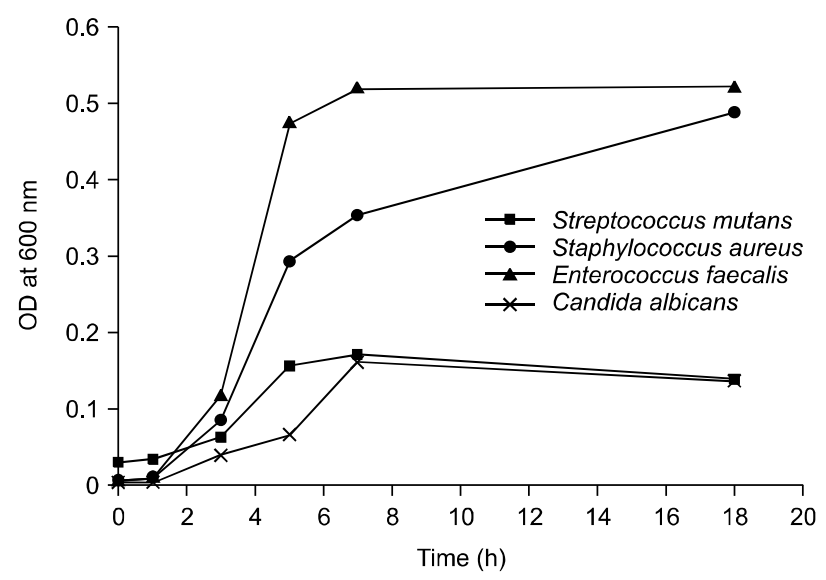

Fig. 2. Growth curves of four different oral microorganisms. Growth was measured in Brain Heart Infusion broth during time $(x-a x i s)$ and expressed as optical density (OD) at the wavelength of $600 \mathrm{~nm}$ (y-axis). The last exponential phase of each microorganism was used for this study. had significantly higher antibacterial activity than that of the others against three different bacteria strains. The high concentration of the P6 sample has also shown an antifungal effect $(\mathrm{p}<0.05)$.

\section{Discussion}

Many microorganisms that inhabit the oral cavity, including bacteria and fungi, may cause oral health problems. Due to the diversity of the oral microbiome, few specific treatments exist. As the focus on health increases, an increasing amount of research is performed on finding alternative treatments. The multifunctional properties of propolis have been applied in oral health products such as mouth rinses and toothpastes ${ }^{16,18,19)}$. Although antibacterial and antifungal effects were found, the evidence was weak and, in some studies, mouth rinse that contained propolis showed no clinical effect ${ }^{20)}$. Thus, in the context of propolis application, further research on the connection between its antimicrobial properties and chemical composition is required.

Flavonoids, aromatic acids, diterpenic acids, and phenolic compounds are known as the major components responsible for the biological activities of propolis and ethanol extracts of propolis ${ }^{21)}$. The flavonoid and phenol content of propolis has been previously studied ${ }^{3,22)}$, and a correlation between them and the effect of propolis has been found; however, the antibacterial effects of propolis could not be described based on its composition.

Table 1. Zones of Inhibition (mm)

\begin{tabular}{|c|c|c|c|c|c|c|c|c|}
\hline & & \multicolumn{6}{|c|}{6 different regions in Korea } & \multirow{2}{*}{$\mathrm{p}$} \\
\hline & & $\mathrm{P} 1$ & $\mathrm{P} 2$ & P3 & $\mathrm{P} 4$ & P5 & P6 & \\
\hline \multirow[t]{4}{*}{ PE $10 \mathrm{mg} / \mathrm{ml}$} & S. mutans & $9.10 \pm 0.17^{\mathrm{a}}$ & $8.55 \pm 0.13^{\mathrm{a}, \mathrm{b}}$ & $8.97 \pm 0.45^{\mathrm{a}}$ & $8.08 \pm 0.28^{\mathrm{b}, \mathrm{c}}$ & $8.07 \pm 0.21^{\mathrm{b}}$ & $8.97 \pm 0.26^{\mathrm{a}}$ & 0.001 \\
\hline & S. aureus & $7.50 \pm 0.13^{c}$ & $7.48 \pm 0.19^{\mathrm{a}, \mathrm{b}}$ & $7.62 \pm 0.15^{\mathrm{c}}$ & $8.05 \pm 0.09^{b, c}$ & $8.32 \pm 0.18^{\mathrm{b}}$ & $8.30 \pm 0.30^{\mathrm{a}}$ & 0.000 \\
\hline & E. faecalis & $7.47 \pm 0.29^{\mathrm{b}, \mathrm{c}}$ & $7.25 \pm 0.22^{\mathrm{c}}$ & $7.68 \pm 0.20^{\mathrm{a}, \mathrm{b}, \mathrm{c}}$ & $7.72 \pm 0.28^{\mathrm{a}, \mathrm{b}, \mathrm{c}}$ & $8.07 \pm 0.33^{\mathrm{a}, \mathrm{b}}$ & $8.28 \pm 0.28^{\mathrm{a}}$ & 0.005 \\
\hline & C. albicans & $7.93 \pm 0.51^{\mathrm{a}}$ & $7.97 \pm 0.42^{\mathrm{a}}$ & $7.65 \pm 0.22^{\mathrm{a}}$ & $7.98 \pm 0.13^{\mathrm{a}}$ & $8.20 \pm 0.23^{\mathrm{a}}$ & $8.32 \pm 0.16^{\mathrm{a}}$ & 0.211 \\
\hline \multirow[t]{4}{*}{$\mathrm{PE} 50 \mathrm{mg} / \mathrm{ml}$} & S. mutans & $9.97 \pm 0.65^{\mathrm{b}}$ & $9.33 \pm 0.38^{\mathrm{b}, \mathrm{c}}$ & $10.43 \pm 0.81^{\mathrm{b}}$ & $10.32 \pm 0.30^{\mathrm{b}}$ & $9.83 \pm 0.57^{\mathrm{b}}$ & $10.88 \pm 0.39^{\mathrm{a}, \mathrm{b}}$ & 0.060 \\
\hline & S. aureus & $8.17 \pm 0.23^{\mathrm{c}}$ & $7.94 \pm 0.13^{\mathrm{c}}$ & $8.17 \pm 0.12^{\mathrm{c}}$ & $8.72 \pm 0.14^{\mathrm{b}}$ & $8.77 \pm 0.32^{\mathrm{b}}$ & $9.38 \pm 0.18^{\mathrm{a}}$ & 0.000 \\
\hline & E. faecalis & $7.88 \pm 0.25^{\mathrm{b}, \mathrm{c}}$ & $8.03 \pm 0.15^{\mathrm{b}}$ & $8.13 \pm 0.19^{b}$ & $8.68 \pm 0.43^{\mathrm{a}, \mathrm{b}}$ & $8.42 \pm 0.25^{\mathrm{b}}$ & $8.50 \pm 0.30^{\mathrm{b}}$ & 0.029 \\
\hline & C. albicans & $7.95 \pm 0.18^{\mathrm{b}}$ & $8.35 \pm 0.49^{b}$ & $7.78 \pm 0.51^{\mathrm{b}}$ & $8.12 \pm 0.13^{b}$ & $8.25 \pm 0.30^{\mathrm{b}}$ & $9.33 \pm 0.1^{\mathrm{a}}$ & 0.001 \\
\hline
\end{tabular}

Values are presented as mean \pm standard deviation. All experiments were repeated at least 3 times independently.

P1: Uijeongbu, P2: Ansan, P3: Hongcheon, P4: Iksan, P5: Gwangju, P6: Sangju, PE: propolis extracts, S. mutans: Streptococcus mutans, S. aureus: Staphylococcus aureus, E. faecalis: Enterococcus faecalis, C. albicans: Candida albicans.

${ }^{\mathrm{a} \sim \mathrm{c}}$ Values in the same row with different superscript small letters are significantly different at $\mathrm{p}<0.05$. 

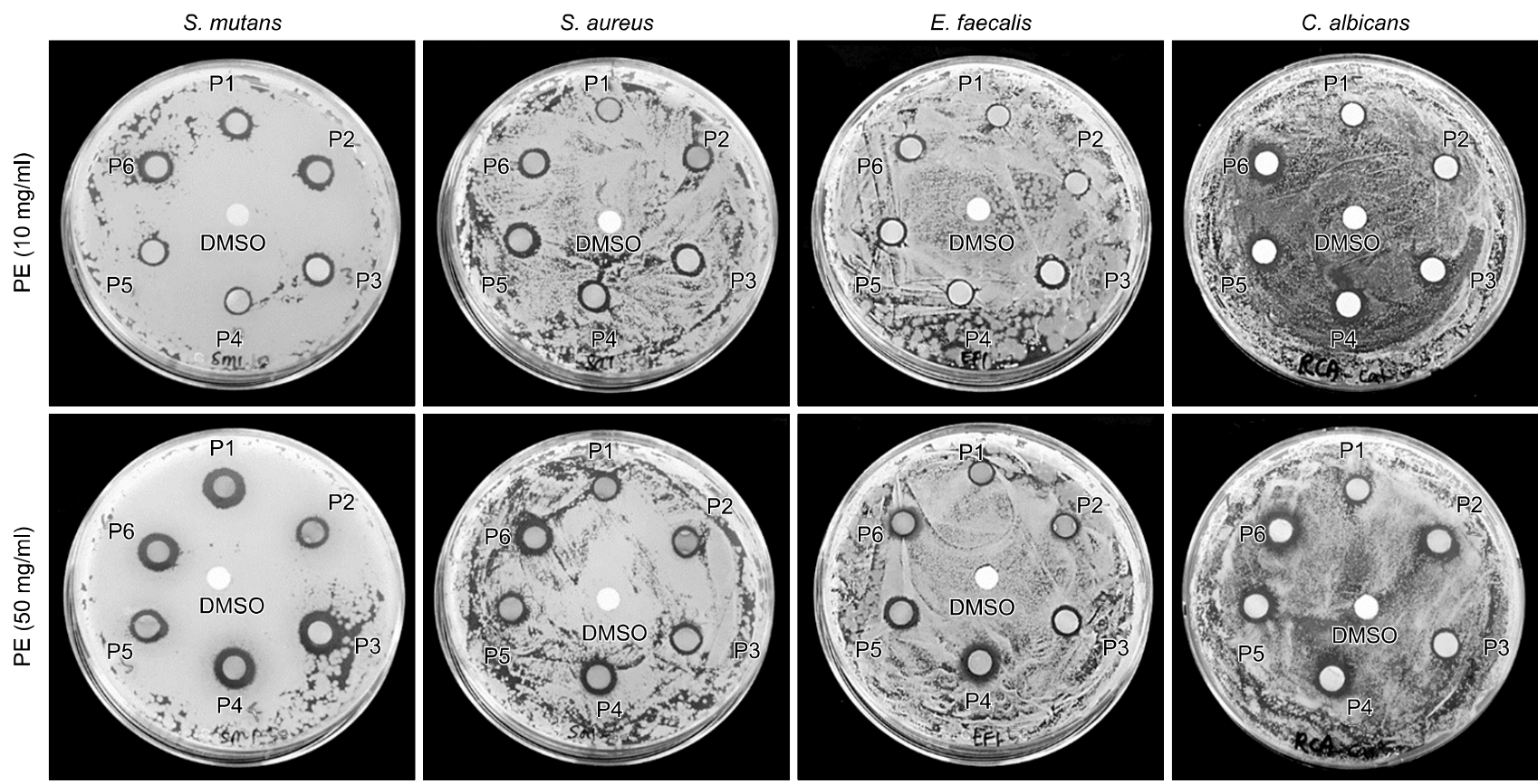

Fig. 3. Antimicrobial activity of propolis extracts (PE) from regions $P 1 \sim P 6$ on four different oral microorganisms. Filter papers with 10 or $50 \mathrm{mg} / \mathrm{ml}$ of propolis extracts were placed on respective microorganism-inoculated agar plates, and incubated at $37^{\circ} \mathrm{C}$ for 24 hours. The samples were placed clockwise from P1 (the top of the plate) to P6, the negative controls being placed in the middle of the agar plates. All tests were conducted in triplicate. S. mutans. Streptococcus mutans, S. aureus. Staphylococcus aureus, E. faecalis. Enterococcus faecalis, C. albicans: Candida albicans, P1: Uijeongbu, P2: Ansan, P3: Hongcheon, P4: Iksan, P5: Gwangju, P6: Sangju, DMSO: dimethyl sulfoxide.

Furthermore, the solution used for propolis extraction also influences the contents of propolis, in turn affecting the effects of propolis. Various basic solvents such as ethanolic base, aqueous base, and glycolic extracts are used for propolis extraction. In one study, the antibacterial effect of aqueous propolis on Streptococcus mitis has been demonstrated. It was also found that the glycol extract of propolis, associated with calcium hydroxide, was able to completely eliminate E. faecalis and C. albicans ${ }^{177}$.

Ethanolic extracts of propolis samples showed high inhibitory effects against Gram-positive cocci (S. mutans, $S$. aureus, and E. faecalis), but had a weak effect against yeast (C. albicans). In addition, low activity against Gram-negative cocci has been previously reported ${ }^{21)}$. The cariogenic process of $S$. mutans was disturbed by propolis, and its plaque index and polysaccharide formation were reduced in in vivo studies ${ }^{23)}$. Duarte et al. ${ }^{24)}$ suggested that the cariostatic properties of propolis are associated with its effect on acid production and the acid tolerance of streptococci.

In the present study, all samples showed the highest antibacterial effect on $S$. mutans at both concentrations, and, among the samples, P4 showed the highest effect. P4 and P6 had an antibacterial effect against $S$. aureus, while P4, P5, and P6 had an antibacterial effect against $E$. faecalis. Interestingly, all test samples showed a similar antifungal effect against $C$. albicans at both concentration; however, P6 showed a significantly higher, concentrationdependent effect. In particular, the propolis sample collected in Sangju (P6) showed a stronger antibacterial activity than the samples collected in the other areas. Finally, all samples showed significant results compared to the control results.

Unlike for many natural-based remedies, data on the biological effects and toxicity of propolis with regard to allergic reactions do exist. Regarding allergic reactions, propolis is relatively non-toxic ${ }^{2}$. Although the composition of Korean propolis has been shown to be similar to that from other countries, the differences in its chemical composition based to its geographical distribution pattern make it difficult to commercialize it clinically. Therefore, further studies are needed to determine the quality and 
safety control criteria for propolis for its routine clinical use.

\section{Acknowledgements}

Mok-Ryeon Ahn in Dong-A University provided the Korean propolis samples for this study.

\section{References}

1. Bankova VS, de Castro SL, Marcucci M: Propolis: recent advances in chemistry and plant origin. Apidologie 31: 3-15, 2000. https://doi.org/10.1051/apido:2000102

2. Burdock GA: Review of the biological properties and toxicity of bee propolis (propolis). Food Chem Toxicol 36: 347-363, 1998. https://doi.org/10.1016/S0278-6915(97)00145-2

3. Ahn MR, Kumazawa S, Hamasaka T, Bang KS, Nakayama T: Antioxidant activity and constituents of propolis collected in various areas of Korea. J Agric Food Chem 52: 7286-7292, 2004. https://doi.org/10.1021/jf048726s

4. Liao Y, Brandt BW, Li J, Crielaard W, Van Loveren C, Deng DM: Fluoride resistance in Streptococcus mutans: a mini review. J Oral Microbiol 9: 1344509, 2017. https://doi.org/10.1080/20002297.2017.1344509

5. Cancio V, Carvalho Ferreira D, Cavalcante FS, et al.: Can the Enterococcus faecalis identified in the root canals of primary teeth be a cause of failure of endodontic treatment? Acta Odontol Scand 75: 423-428, 2017. https://doi.org/10.1080/00016357.2017.1328742

6. Gomes BP, Pinheiro ET, Sousa EL, et al.: Enterococcus faecalis in dental root canals detected by culture and by polymerase chain reaction analysis. Oral Surg Oral Med Oral Pathol Oral Radiol Endod 102: 247-253, 2006. https://doi.org/10.1016/j.tripleo.2005.11.031

7. Gajan EB, Aghazadeh M, Abashov R, Salem Milani A, Moosavi Z: Microbial flora of root canals of pulpally-infected teeth: enterococcus faecalis a prevalent species. J Dent Res Dent Clin Dent Prospects 3: 24-27, 2009. https://doi.org/10.5681/joddd.2009.007

8. Fritschi BZ, Albert-Kiszely A, Persson GR: Staphylococcus aureus and other bacteria in untreated periodontitis. J Dent Res 87: 589-593, 2008 https://doi.org/10.1177/154405910808700605
9. Kim GY, Lee $\mathrm{CH}$ : Antimicrobial susceptibility and pathogenic genes of Staphylococcus aureus isolated from the oral cavity of patients with periodontitis. J Periodontal Implant Sci 45: 223-228, 2015. https://doi.org/10.5051/jpis.2015.45.6.223

10. Nobile CJ, Johnson AD: Candida albicans biofilms and human disease. Annu Rev Microbiol 69: 71-92, 2015. https://doi.org/10.1146/annurev-micro-091014-104330

11. Azevedo RVP, Komesu MC, Candido RC, Salvetti C, Rezende FHC: Candida sp in the oral cavity with and without lesions: maximal inhibitory dilution of propolis and periogard. Rev Microbiol 30: 335-341, 1999. https://doi.org/10.1590/S0001-37141999000400008

12. Jeon ES, Yoon SH, Han MD: Antimicrobial activity of Streptococcus mutans by herbal medicine extracts. J Dent Hyg Sci 2: 31-38, 2002.

13. Lee DJ, Han IM, Kim WJ, Cho IS: Anti-microbial, anti-inflammatory and anti-oxidative effects of herbal medicine extracts as anti-gingivitis ingredient. J Dent Hyg Sci 10: 25-29, 2010.

14. Kim SI, Jeong MJ, Ahn YS, Kim AR, Kim MN, Lim DS: Antimicrobial effect of commercially available mouth rinsing solutions and natural herbal extracts on Streptococcus mutans. J Dent Hyg Sci 15: 308-317, 2015.

https://doi.org/10.17135/jdhs.2015.15.3.308

15. Park YK, Koo MH, Abreu JA, Ikegaki M, Cury JA, Rosalen PL: Antimicrobial activity of propolis on oral microorganisms. Curr Microbiol 36: 24-28, 1998.

16. Ozan F, Sümer Z, Polat ZA, Er K, Ozan U, Deger O: Effect of mouthrinse containing propolis on oral microorganisms and human gingival fibroblasts. Eur J Dent 1: 195-201, 2007.

17. Bezerra AMF, de Farias MdCAD, Bezerra KKS, et al.: Action of propolis on microorganisms of the oral cavity: an integrative review. Int Arch Med 8: 1-13, 2015.

18. Wiatrak K, Morawiec T, Rój R, et al.: Oral health of patients treated with acrylic partial dentures using a toothpaste containing bee product. Evid Based Complement Alternat Med 2017: 4034179, 2017. https://doi.org/10.1155/2017/4034179

19. de Camargo Smolarek P, Esmerino LA, Chibinski AC, Bortoluzzi MC, Dos Santos EB, Kozlowski VA Jr: In vitro antimicrobial evaluation of toothpastes with natural compounds. Eur J Dent 9: 580-586, 2015. 
https://doi.org/10.4103/1305-7456.172632

20. Vanni R, Waldner-Tomic NM, Belibasakis GN, Attin T, Schmidlin PR, Thurnheer T: Antibacterial efficacy of a propolis toothpaste and mouthrinse against a supragingival multispecies biofilm. Oral Health Prev Dent 13: 531-535, 2015. https://doi.org/10.3290/j.ohpd.a34372

21. Silici S, Kutluca S: Chemical composition and antibacterial activity of propolis collected by three different races of honeybees in the same region. J Ethnopharmacol 99: 69-73, 2005. https://doi.org/10.1016/j.jep.2005.01.046

22. Choi SJ, Shimomura K, Kumazawa S, Ahn MR: Antioxidant properties and phenolic composition of propolis from diverse geographic regions in Korea. Food Sci Technol Res 19: 211-222, 2013. https://doi.org/10.3136/fstr.19.211

23. Libério SA, Pereira AL, Araújo MJ, et al.: The potential use of propolis as a cariostatic agent and its actions on mutans group streptococci. J Ethnopharmacol 125: 1-9, 2009. https://doi.org/10.1016/j.jep.2009.04.047

24. Duarte S, Rosalen PL, Hayacibara MF, et al.: The influence of a novel propolis on mutans streptococci biofilms and caries development in rats. Arch Oral Biol 51: 15-22, 2006. https://doi.org/10.1016/j.archoralbio.2005.06.002 